\title{
TOWARD A VETERAN-CENTRIC VIEW ON COMMUNITY (RE)INTEGRATION
}

\author{
Theresa Crocker, PhD, RD; Gail Powell-Cope, PhD, ARNP, FAAN; Lisa M. Brown, PhD; Karen Besterman- \\ Dahan, PhD, RD
}

\section{INTRODUCTION}

esearch on postdeployment health is critical to inform the development and dissemination of health services for Veterans. Since September 11, 2001, more than 2.2 million men and women have served in Operation Iraqi Freedom (OIF), Operation Enduring Freedom (OEF), and Operation New Dawn (OND) [1]. In contrast with prior conflicts, servicemembers experienced more repeat tours, greater perceived level of danger due to the continuous risk of unconventional means of warfare, and diverse military cultures serving together [2]. The effects of these circumstances on Veterans' lives over time are not clear; however, as early as 2007, Resnik and Allen observed that a significant number were at risk of poor community reintegration upon returning home from deployment [3]. Following a comprehensive review of the literature, this guest editorial provides a synopsis of the current state of research related to community "(re)integration" in OIF/OEF/OND servicemembers and Veterans that can serve to advance the science. It includes discussion of advances in defining and measuring community (re)integration, stakeholder response, and emerging needs.

\section{THE CHALLENGES}

Approximately 44 percent of returning servicemembers and Veterans reported a range of difficulties readjusting to postdeployment status [1]. "Coming home" is an immersive experience, involving all realms of life and influencing health and well-being [4]. Many servicemembers and Veterans encounter the interrelated and simultaneous tasks of processing combat experiences while reentering a civilian life that has changed in their absence. Difficulty with community reintegration is associated with worse overall mental health [5]. Comorbid mental health disorders such as posttraumatic stress disorder (PTSD), anxiety, depression, and alcohol and substance abuse that resulted from or were exacerbated by combat exposure have been reported [2]. Increased rates of suicide and a changing face of homeless Veterans have been noted in recent literature [6-7]. Resuming predeployment life roles can be especially challenging for servicemembers and Veterans who sustained physical injury, an unfortunate reality in this cohort where traumatic brain injury (TBI) and motor vehicle accidents are common [8]. The disability associated with physical and psychological injury is far reaching, affecting self-care, employment, education, relationships, marriages, finances, home, and civic and community life [8-10]. The reality that issues can exist in isolation or in combination further complicates the transition back home and increases the likelihood that no two experiences are identical.

\section{DEFINING (RE)INTEGRATION}

The terms community "integration" and community "reintegration" are frequently used interchangeably in the literature, even within the same article. For over 30 years, health service providers and researchers have attempted to define these terms [11]. Though usually in reference to rehabilitation outcomes, elements of each are relevant and applicable when discussing the transition from deployment to "home." Community integration has been described as participation in life roles [10] and the return of individuals to their age-, sex-, and culturally appropriate role functions [3]. Community reintegration has been used to describe a return to participation in life roles following discharge from an institution where one was separated from normal community living and then returns to life in a community. It has also been used to describe repatriation from a foreign county [10]. Reistetter and Abreu described reintegration as an 
adaptation process that is multidimensional, dynamic, personal, and culturally bound [12].

The ultimate goal of any rehabilitation effort is to help those who have been injured adjust to life in the community [11]. While rehabilitation may not seem immediately relevant to those without physical injury, adjustment to life in their community is a reasonable goal for all who are transitioning postdeployment. Whereas the Department of Defense does not have a uniform definition of reintegration, its postdeployment programs emphasize areas including relationships, employment or schooling, access to benefits, healthcare, and housing; in other words, domains relevant to full participation in community life [5]. Though variance in definition exists, the consensus of the articles included in this review of the literature reveals that similar to the goals of TBI rehabilitation, servicemembers and Veterans who have successfully (re)integrated postdeployment are productive participants at home, their place of work or school, and within their community [13]. Recognizing that successful (re)integration has a subjective component, this definition of community (re)integration will be used for the purposes of this guest editorial. The inconsistency in use of the terms integration and reintegration reflects the literature and is reported as the authors intended in the sections that follow.

\section{MEASURING (RE)INTEGRATION}

In addition to variance in defining successful community (re)integration, differences are noted in its measurement in both Veteran and non-Veteran populations [10]. Determining the extent and nature of disability faced is critical in developing interventions that best meet the needs of the servicemembers and Veterans who return from conflict $[10,14]$. Yet, gaps in measurement complicate this task. To date, no gold standard exists to assess community (re)integration in this population [10]. Though measurement tools exist, they differ in conceptual basis, the vantage point of analysis (subjective vs objective), target population (those with neurological disorders, Veteran, etc.), ease of use or burden, indication (clinical or research), constructs measured, and psychometric validation. The difficulty in measurement is compounded by the fact that not all wounds are physically visible in this group, and psychological injuries may also interfere with the ser- vicemembers' and Veterans' experience upon returning home.

The International Classification of Functioning, Disability and Health (ICF) is a systematic and universal framework used to describe the full range of human functioning and possible effects of various health conditions. It can be applied to all people, regardless of disability [15], and is frequently used as a framework for outcomes measurement. In addition, several population-specific instruments have been developed to measure aspects of community reintegration for people with a history of stroke, spinal cord injury, or TBI. Examples of this are the Community Integration Measure, the Craig Handicap Assessment and Reporting Technique, and the Community Integration Questionnaire, which are further described elsewhere [10-12]. Until recently, no tools were designed specifically for use with OIF/OEF/OND Veterans. In 2007, the lack of a brief, psychometrically sound measure of reintegration postdeployment was suggested as a factor contributing to a lack of research on the reintegration issues faced by servicemembers and their families [16]. Department of Veterans Affairs (VA) researchers similarly identified this need and responded.

Using the ICF to understand problems faced by OIF/ OEF Veterans, Resnik and Allen reported many similarities in the issues faced by those with and without polytraumatic injuries [3]. They found that none of the available measures comprehensively addressed the specific needs identified by OIF/OEF Veterans, prompting development of the Community Reintegration for Service Members (CRIS), a tool designed to specifically incorporate issues relevant to injured servicemembers [10]. The CRIS has been validated for use in person and via telephone [8] and has a computer-adapted version [14]. Sayer et al. reported that most reintegration measures are intended for those with neurological disorders and might not be relevant to those without physical handicaps or specialized rehabilitation needs, prompting the development of the Military to Civilian Questionnaire [5]. This tool was designed to assess specific community reintegration problems faced by OIF/ OEF combat Veterans and may be useful in research protocols. Additional outcomes research and validation for use in clinical settings is needed [5].

Though the science of measuring community (re)integration in OIF/OEF/OND Veterans is advancing, questions about the best timing for measurement and most appropriate tool remain unanswered. A review 
by Reistetter and Abreu indicated that following a TBI, community integration does not begin to stabilize until at least $1 \mathrm{yr}$ postinjury, and it is quite possible that stabilization postdeployment requires some time for servicemembers and Veterans as well [12]. They also suggested that researchers need to consider community integration outcomes of interest when deciding which measure to use [12]. Missing from either of the aforementioned, more Veteran-specific, measurement tools is the subjective voice of the servicemember and Veteran. By capturing this perspective, researchers, clinicians, and policymakers can have an enhanced understanding of the environmental barriers and facilitators influencing the resumption of desired community roles.

\section{STAKEHOLDER RESPONSE}

All branches of the military have programs dedicated to providing assistance to servicemembers and Veterans with combat-related injuries or illnesses resulting from their involvement in the OIF/OEF/OND conflicts [17]. Helping this cohort of Veterans to adjust and return to full participation in community life roles is also a VA research priority $[8,10]$. Since September 2001, the VA has responded to the needs of returning servicemembers and Veterans in several ways. For example, in 2008, the State of the Art (SOTA) conference on TBI convened and sought to advance knowledge gaps and determine relevant research questions to advance the understanding and treatment of TBI via several topical foci, including community integration for those with TBI [18]. The National Center for PTSD is dedicated to research and education on trauma and PTSD, working to assure that the latest research findings help those exposed to trauma [19]. The VA Health Services Research and Development Service (HSR\&D) Polytrauma/Blast-Related Injury (PT/BRI) Quality Enhancement Research Initiative (QUERI) promotes the successful rehabilitation, psychological adjustment, and community reintegration for individuals with PT/BRIs through implementation activities [20]. Gaps identified by this QUERI included the lack of documentation of the clinical challenges and needs of patients with polytrauma and their families. The SOTA conference on outcome measures in rehabilitation convened in January 2010 to address the clinical complexity and long-term nature of injuries faced by this cohort of Veterans [21]. A Working Group on Community Reintegration identified concerns and dimensions of community reintegration that could or should be measured, provided suggestions to improve measurement, made suggestions for future research focused on outcome measures for community integration efforts, and made policy recommendations to facilitate this area of research within the VA [10].

Research is being conducted to identify the treatment needs and address barriers to (re)integration faced by OIF/OEF/OND Veterans who are receiving care at the VA and beyond. A recent search of HSR\&D research studies and implementation projects using the search term "community reintegration" revealed 28 unique projects funded from 2007 to 2016 [22]. Of the 28 projects, 25 were specific to OIF/OEF/OND Veterans. Further describing the projects, 15 utilized mixed or qualitative methods while 10 were quantitatively focused. How these and other efforts translate into practice and policy on many of these important issues remains to be seen.

\section{EMERGING NEEDS}

Findings to date suggest that Veterans are interested in information and interventions to help their readjustment to community life [23]. The use of technology has been suggested as one way to facilitate communication via email, chat rooms, bulletin boards, and instant messaging [2]. Hinojosa and Hinojosa highlighted the significance of military friendships in dealing with the challenges of deployment and suggest that they may serve an important role in postdeployment reintegration [24]. Connections with others and choosing to have a positive attitude have also been reported as methods utilized in an attempt to resolve issues faced upon return home [4]. Despite efforts by Federal and state governments to implement programs that address reintegration difficulties and promote community (re)integration postdeployment, evaluation of the effectiveness of these programs is lacking [23,25-26]. The need for concentrated efforts to advance the science of measurement of community reintegration is recognized [10]. The identification of the critical elements of participation for specific groups of Veterans 
has been recommended by the 2012 Working Group on Community Reintegration.

Areas that would benefit from further investigation include an exploration of the subjective experience and varying needs of several cohorts. This includes, but is not limited to, those with nontraditional family structures [1], those whose identification or help-seeking is limited by stigma [25], and those from racial and ethnic minority backgrounds who may face additional difficulties with (re)integration $[5,27]$. Further, exploration of the variance in experience between Active Duty and National Guard/Reserve Veterans [5,28-29], between returning male and female servicemembers $[5,28,30]$, and assessment of the community (re)integration needs of those Veterans who are not patients in rehabilitation settings [5] is also recommended.

Identifying the most effective vocational and family support approaches is viewed as critical to successful community integration [13]. Additionally, as far as we are aware, an assessment of the attitudes and experiences of key supporters in the Veteran's life remains a void. Much research is being focused on those who receive services from within the VA system of care, while less is known about the Veterans who seek care outside of VA facilities [31]. This is important because a recent article by Sayer et al. reported that approximately 56 percent of OIF/OEF/OND Veterans were not enrolled in the VA and that of those enrolled, 40 percent were not classified as combat Veterans [23]. An additional concern is that many of the problems reported to date are out of the realm of traditional medical practice. As a result, Sayer et al. cautioned that mental health practitioners may be overwhelmed by the demand for services [23]. Finley et al. suggested that primary care clinicians may play an important link in the identification of those who may be experiencing difficulties upon return from deployment and are not currently receiving care within the VA system of care [31]. The experience of each of these cohorts has either not been studied extensively, has been identified as potentially benefitting from future study, or is in areas where past research is varied or inconclusive.

\section{A NEW PERSPECTIVE}

As noted, research on postdeployment health is critical to inform the development and dissemination of health services. The 2010 SOTA conference on outcome measures in rehabilitation recognized the need to identify and understand factors affecting the outcome of rehabilitation interventions. Work by Sayer et al. identified the need for more in-depth study of the complications faced by returning Veterans and their preferences for interventions [23]. Despite the availability of medical treatments and rehabilitation to address the physical causalities of conflict, basic knowledge of the personal and socially meaningful outcomes of those with complications and their families is still lacking [32]. Just as disability occurs within a social context and is best understood as the interplay between the individual and his or her environment [14], the transition of (re)integration is likely best understood by considering these overlapping contexts as well. Wands reported that a noteworthy void in the research is the exploration of the Veteran's subjective experience with reintegration, including the strategies used to successfully navigate the transition from the battlefield to home [4]. Explanatory models (e.g., the social and cultural construction of illness in contrast with the medical understanding of disease) have been used to ensure the provision of patient-centered care in a variety of health-related contexts [33] and would be useful to expand understanding of the subjective experience of servicemember and Veteran (re)integration as well.

While randomized controlled trials of community (re)integration intervention are needed to demonstrate personal and system outcomes, the successes and failures of rehabilitation interventions are not fully understood through quantitative means alone [21]. Similarly, while quantitative measures capture the extent of disability or struggle associated with (re)integration, they are limited in the capacity to identify solutions or ways to best meet the needs of those experiencing difficulties in their postdeployment roles. A social ecological model of health [34], uniting the Veteran's behaviors and interactions with his or her sociocultural and physical environments, would help to deepen the understanding of the postdeployment experience and facilitate the development of innovative strategies and solutions. Acknowledging how differences in sex, age, culture, and experience influence the transition and engaging participants in developing meaningful solutions to 
XV

problems [35] are critical in advancing the science of (re)integration.

In an October 2013 newsletter, David Atkins, Director of VA HSR\&D, wrote, "A big challenge for research and health care systems is to develop and test effective programs that can either promote a healthy culture or improve a dysfunctional one." He recognized the numerous ways that health services research and the contributions to HSR\&D and QUERI projects made by anthropologists expand our understanding of healthcare culture and culture change by illuminating aspects that may serve to either facilitate or impede efforts to improve care [36]. Qualitative and mixed methods programs of research provide multiple means to identify barriers and facilitators to community (re)integration, provide feedback on feasibility and acceptability during program development, and evaluate the effectiveness of programs that may already be in place. Additionally, this type of research can assist clinicians in the development of new therapies and provide a living example, which can be used by VA operations to influence policy makers. The results of the recent search of HSR\&Dfunded research studies and implementation projects suggests that support exists for qualitative and mixed methods programs of research within the VA. The VA Working Group on Community Reintegration recognized that successful community reintegration will be dependent on bridging the gaps between the alienation felt by returning Veterans and community expectations. Mixed research methodologies offer a vehicle to reduce this disjuncture [10].

\section{Theresa Crocker, PhD, RD; ${ }^{1 *}$ Gail Powell-Cope, PhD, ARNP, FAAN; ${ }^{1}$ Lisa M. Brown, PhD; $;^{1-2}$ Karen Besterman-Dahan, PhD, RD ${ }^{1}$ \\ ${ }^{1}$ VA HSR\&D/Rehabilitation Research and \\ Development Service Center of Innovation on Disability and Rehabilitation Research, James A. Haley Veterans' Hospital and Clinics, Tampa, FL; ${ }^{2}$ School of Aging Studies, College of Behavioral and Community Sciences, University of South Florida, Tampa, FL}

*Email: Theresa.Crocker@va.gov

\section{REFERENCES}

1. Committee on the Assessment of Readjustment Needs of Military Personnel, Veterans, and Their Families;
Board on the Health of Select Populations. Returning home from Iraq and Afghanistan: Assessment of readjustment needs of veterans, service members, and their families. Washington (DC): Institute of Medicine of the National Academies, The National Academies Press; 2013.

2. Manderscheid RW. Helping veterans return: community, family, and job. Arch Psychiatr Nurs. 2007;21(2):12224. [PMID:17397697]

http://dx.doi.org/10.1016/j.apnu.2006.12.006

3. Resnik L, Allen SM. Using International Classification of Functioning, Disability and Health to understand challenges in community reintegration of injured veterans. J Rehabil Res Dev. 2007;44(7):991-1006. [PMID:18075956] http://dx.doi.org/10.1682/JRRD.2007.05.0071

4. Wands L. "No one gets through it OK": The health challenge of coming home from war. ANS Adv Nurs Sci. 2013;36(3):186-99. [PMID:23907301] http://dx.doi.org/10.1097/ANS.0b013e31829edcbe

5. Sayer NA, Frazier P, Orazem RJ, Murdoch M, Gravely A, Carlson KF, Hintz S, Noorbaloochi S. Military to civilian questionnaire: A measure of postdeployment community reintegration difficulty among veterans using Department of Veterans Affairs medical care. J Trauma Stress. 2011;24(6):660-70. [PMID:22162082] http://dx.doi.org/10.1002/jts.20706

6. Harrell MC, Berglass N. Losing the battle: The challenge of military suicide [Internet]. Washington (DC): Center for a New American Security; 2011 [cited 2013 Dec 17]. Available from: http://kms1.isn.ethz.ch/serviceengine/ Files/ISN/134843/ipublicationdocument singledocument/2558ece9-3c9c-4cbb-acf0-5cb0f$826 \mathrm{~cd} 3 \mathrm{e} / \mathrm{en} / \mathrm{CNAS}$ LosingTheBattle HarrellBerglass.pdf

7. Tsai J, Pietrzak RH, Rosenheck RA. Homeless veterans who served in Iraq and Afghanistan: Gender differences, combat exposure, and comparisons with previous cohorts of homeless veterans. Adm Policy Ment Health. 2013;40(5):400-405. [PMID:22824909] http://dx.doi.org/10.1007/s10488-012-0431-y

8. Resnik LJ, Clark MA, Borgia M. Telephone and face to face methods of assessment of veteran's community reintegration yield equivalent results. BMC Med Res Methodol. 2011;11(1):98. [PMID:21703000] http://dx.doi.org/10.1186/1471-2288-11-98

9. Ellison ML, Mueller L, Smelson D, Corrigan PW, Torres Stone RA, Bokhour BG, Najavits LM, Vessella JM, Drebing $C$. Supporting the education goals of post-9/11 veterans with self-reported PTSD symptoms: A needs assessment. Psychiatr Rehabil J. 2012;35(3):209-17. [PMID:22246119]

http://dx.doi.org/10.2975/35.3.2012.209.217

10. Resnik L, Bradford DW, Glynn SM, Jette AM, Johnson Hernandez C, Wills S. Issues in defining and measuring veteran community reintegration: Proceedings of the 
Working Group on Community Reintegration, VA Rehabilitation Outcomes Conference, Miami, Florida. J Rehabil Res Dev. 2012;49(1):87-100.

\section{[PMID:22492341]}

http://dx.doi.org/10.1682/JRRD.2010.06.0107

11. McColl MA, Davies D, Carlson P, Johnston J, Minnes P. The community integration measure: Development and preliminary validation. Arch Phys Med Rehabil. 2001;82(4):429-34. [PMID:11295000]

http://dx.doi.org/10.1053/apmr.2001.22195

12. Reistetter TA, Abreu BC. Appraising evidence on community integration following brain injury: A systematic review. Occup Ther Int. 2005;12(4):196-217.

[PMID:16485508]

http://dx.doi.org/10.1002/oti.8

13. Kupersmith J, Lew HL, Ommaya AK, Jaffee M, Koroshetz WJ. Traumatic brain injury research opportunities: Results of Department of Veterans Affairs Consensus Conference. J Rehabil Res Dev. 2009;46(6):vii-xvi. [PMID:20104393]

http://dx.doi.org/10.1682/JRRD.2009.06.0079

14. Resnik L, Reiber G. Long-term disabilities associated with combat casualties: Measuring disability and reintegration in combat veterans. J Am Acad Orthop Surg. 2012;20(Suppl 1):S31-34. [PMID:22865133] http://dx.doi.org/10.5435/JAAOS-20-08-S31

15. Reed GM, Lux JB, Bufka LF, Trask C, Peterson DB, Stark S, Threats TT, Jacobson JW, Hawley JA. Operationalizing the International Classification of Functioning, Disability and Health in clinical settings. Rehabil Psychol. 2005; 50(2):122-31.

http://dx.doi.org/10.1037/ 0090-5550.50.2.122

16. American Psychological Association. Presidential task force on military deployment services for youth, families and service members. The psychological needs of US military service members and their families: A preliminary report. Washington (DC): American Pschological Association; 2007.

17. Perla LY, Jackson PD, Hopkins SL, Daggett MC, Van Horn LJ. Transitioning home: Comprehensive case management for America's heroes. Rehabil Nurs. 2013;38(5): 231-39. [PMID:23720383]

http://dx.doi.org/10.1002/rnj.102

18. Kupersmith J, Ommaya AK, Selzer ME, Ruff RL, Lew HL. Guest Editorial: Traumatic brain injury research stateof-the-art conference. J Rehabil Res Dev. 2009;46(6): xvii-xviii. [PMID:20104394]

http://dx.doi.org/10.1682/JRRD.2009.06.0085

19. PTSD: National Center for PTSD [Internet]. Washington (DC): Department of Veterans Affairs; 2014 [updated 2014 Jan 2; cited 2014 Jan 14]. Available from: http:// www.ptsd.va.gov/index.asp

20. Griffin JM, Friedemann-Sánchez G, Hall C, Phelan S, van Ryn M. Families of patients with polytrauma: Understanding the evidence and charting a new research agenda. J Rehabil Res Dev. 2009;46(6):879-92. [PMID:20104409] http://dx.doi.org/10.1682/JRRD.2008.08.0104

21. Elliott TR. Rehabilitation Research and Development state-of-the-art conference on outcome measures in rehabilitation. J Rehabil Res Dev. 2012;49(1):83-86. [PMID:22492340] http://dx.doi.org/10.1682/JRRD.2011.09.0173

22. Health Services Research \& Development. HSR\&D research studies and implementation projects [Internet]. Washington (DC): Department of Veterans Affairs; 2014 [updated 2014 Mar 24; cited 2013 Dec 17]. Available from: http://www.hsrd.research.va.gov/ research/\#.UrBpyOJWuSo

23. Sayer NA, Noorbaloochi S, Frazier P, Carlson K, Gravely A, Murdoch M. Reintegration problems and treatment interests among Iraq and Afghanistan combat veterans receiving VA medical care. Psychiatr Serv. 2010;61(6): 589-97. [PMID:20513682] http://dx.doi.org/10.1176/appi.ps.61.6.589

24. Hinojosa R, Hinojosa MS. Using military friendships to optimize postdeployment reintegration for male Operation Iraqi Freedom/Operation Enduring Freedom veterans. J Rehabil Res Dev. 2011;48(10):1145-58. [PMID:22234660] http://dx.doi.org/10.1682/JRRD.2010.08.0151

25. Danish SJ, Antonides BJ. The challenges of reintegration for service members and their families. Am J Orthopsychiatry. 2013;83(4):550-58.

[PMID:24164527]

http://dx.doi.org/10.1111/ajop.12054

26. Lester P, Saltzman WR, Woodward K, Glover D, Leskin GA, Bursch B, Pynoos R, Beardslee W. Evaluation of a family-centered prevention intervention for military children and families facing wartime deployments. Am J Public Health. 2012;102(Suppl 1):S48-54. PMID:22033756] http://dx.doi.org/10.2105/AJPH.2010.300088

27. Wehman P, Gentry T, West M, Arango-Lasprilla JC. Community integration: Current issues in cognitive and vocational rehabilitation for individuals with $A B I$. J Rehabil Res Dev. 2009;46(6):909-18. 
xvii

CROCKER et al. Guest Editorial

[PMID:20104411]

http://dx.doi.org/10.1682/JRRD.2008.08.0105

28. Erbes CR, Kaler ME, Schult T, Polusny MA, Arbisi PA. Mental health diagnosis and occupational functioning in National Guard/Reserve veterans returning from Iraq. J Rehabil Res Dev. 2011;48(10):1159-70. [PMID:22234661] http://dx.doi.org/10.1682/JRRD.2010.11.0212

29. Milliken CS, Auchterlonie JL, Hoge CW. Longitudinal assessment of mental health problems among active and reserve component soldiers returning from the Iraq war. JAMA. 2007;298(18):2141-48. [PMID:18000197] http://dx.doi.org/10.1001/jama.298.18.2141

30. Crum-Cianflone NF, Jacobson I. Gender differences of postdeployment post-traumatic stress disorder among service members and veterans of the Iraq and Afghanistan conflicts. Epidemiol Rev. 2014;36(1):5-18. [PMID:23988441]

http://dx.doi.org/10.1093/epirev/mxt005

31. Finley EP, Zeber JE, Pugh MJ, Cantu G, Copeland LA, Parchman ML, Noel PH. Postdeployment health care for returning OEF/OIF military personnel and their social networks: A qualitative approach. Mil Med. 2010; 175(12):953-57. [PMID:21265301] http://dx.doi.org/10.7205/MILMED-D-10-00040

32. Messinger SD, Luborsky M. Developing a meaningful life: Social reintegration of service-members and veterans with spinal cord injury. Baltimore (MD): University of Maryland, Baltimore County; 2012.

33. Kleinman A, Eisenberg L, Good B. Culture, illness, and care: Clinical lessons from anthropologic and crosscultural research. Ann Intern Med. 1978;88(2):251-58.
[PMID:626456]

http://dx.doi.org/10.7326/0003-4819-88-2-251

34. Sallis JF, Owen N, Fisher EB. Ecological models of health behavior. In: Glanz K, Rimer BK, Viswanath K, editors. Health behavior and health education: Theory, research, and practice. 4th ed. San Francisco (CA): John Wiley \& Sons Inc; 2008. p. 465-86.

35. Sander AM, Clark A, Pappadis MR. What is community integration anyway?: Defining meaning following traumatic brain injury. J Head Trauma Rehabil. 2010;25(2): 121-27. [PMID:20134333] http://dx.doi.org/10.1097/HTR.0b013e3181cd1635

36. Atkins D. Director's letter [Internet]. Washington (DC): Department of Veterans Affairs; 2013 [cited 2014 Jan 14]. Available from: http://www.hsrd.research.va.gov/ publications/forum/oct13/oct13-director.cfm\#. UtUplrRWuSp

This article and any supplementary material should be cited as follows:

Crocker T, Powell-Cope G, Brown L, Besterman-Dahan $K$. Toward a Veteran-centric view on community (re)integration. J Rehabil Res Dev. 2014;51(3):xi-xviii. http://dx.doi.org/10.1682/JRRD.2014.01.00111

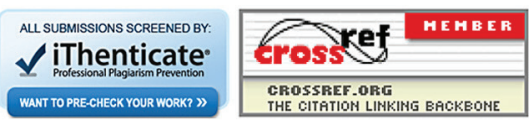

